DOI: 10.20472/IAC.2018.043.039

TAKAKO SASAKI

Waseda University, Japan

CHUN-TENG HSU

Baihe Junior Highschool, Taiwan

\title{
CHARACTERISTICS OF NON-PARTICIPANTS IN COMMUNITY DEVELOPMENT ACTIVITIES IN TAIWAN, A CASE STUDY OF A RURAL COMMUNITY IN TAINAN
}

\begin{abstract}
:
Participatory Community Development (PCD) is a method to solve problems in a community by residents who have common concern about their community's condition. Taiwan has advanced PCD since the comprehensive community development policy was implemented in 1994. This study aims to clarify characteristics of non-participants in PCD activities based on a certain social dimension.

Previous studies have improved PCD technologies, such as clarifying success factors for the community revitalization and developing measures to support PCD mainly focusing on the participant-group, although some researchers pointed out a PCD problem of which participants were a segment of the residents. However, it would be difficult to ensure the continuity of PCD activities which is an entrance to construct a sustainable community, if specialists just focus on participants. Thus, it is worth focusing on the non-participant and considering its reasons from the viewpoint of PCD study.

The research field is an agricultural village of $R$ district in $B$ division in Tainan-city. The survey was conducted three times from 2011 to 2018. The PCD's leader is a pastor in R district and the research already found that participants were almost all Christians and non-participants were almost all Tao-people as it was stated earlier. Based on non-participants' narratives, the study roughly highlighted characteristics of their daily lives as follows:

1. They revere ancestors as well as Tao's gods. They have a specific time for worship in their house every day. In contrast, they visit a temple in the district twice a month for regular rites. They attend worship alone or as a family and there is usually no occasion to communicate with other residents.

2. They frankly visit each other, while there are no relationships beyond the chatting level.

3. They do not share memories about the family and the temple between generations.

4. They tend to frankly join activities in the district regardless of religions or anything else if they can get information.

Therefore, a characteristic of non-participants can be summarized as a more individual-lifestyle, which is more individualistic than Christian participants who have more opportunities to gather in the church. The results indicate that the non-participation is caused by those lifestyles rather than a difference in religions which is generally said in the area. Moreover, the importance of the social dimension as an influential factor was suggested. A micro-perspective based on the locality will be required more and more in the PCD study.
\end{abstract}

\section{Keywords:}

Participatory community development, Taiwan, Non-participation, The social demension 
JEL Classification: Z00, Z13, R58 